\title{
Ganancia de peso en terneros Brahman y Brangus 1/4, 3/8 y 5/8 desde el nacimiento al destete en Corrientes (Argentina)
}

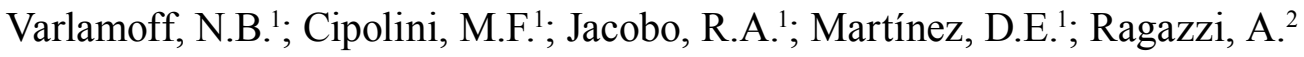 \\ ${ }^{1}$ Cátedra Enfermedades Infecciosas, ${ }^{2}$ Cátedra Producción Bovina, Facultad de Ciencias Veterinarias, UNNE, \\ Sargento Cabral 2139, Corrientes (3400), Argentina. E-mail: enfinf@vet.unne.edu.ar.
}

\begin{abstract}
Resumen
Varlamoff, N.B.; Cipolini, M.F.; Jacobo, R.A.; Martínez, D.E.; Ragazzi, A.: Ganancia de peso en terneros Brahman y Brangus $1 / 4,3 / 8$ y 5/8 desde el nacimiento al destete en Corrientes (Argentina). Rev. vet. 22: 1, 60-63, 2011. En los ambientes tropicales la utilización del cruzamiento de ganado Bos taurus $\mathrm{x}$ Bos indicus es una herramienta de gran utilidad para mejorar los índices productivos de un establecimiento. El clima es un factor que afecta la eficiencia productiva. La Provincia de Corrientes (Argentina) presenta un clima subtropical, con condiciones limitantes para el desarrollo de la ganadería. Estas condiciones del medio determinan la elección de criar animales adaptados, rústicos y con un alto desempeño productivo. Para ello, una opción disponible en la zona es el uso de ganado Bos indicus o sus cruzas. La raza índica más utilizada para este propósito es Brahman. La forma más común de utilizar el ganado índico es en cruzamientos con razas europeas y sintéticas en diferentes proporciones, como el Braford y Brangus 1/4, 3/8, 5/8 y otras. En establecimientos de la zona se ha observado que la hacienda en muchos casos presenta características fenotípicas de $1 / 4$ sangre Bos indicus y esto puede traer como consecuencia una pérdida de adaptabilidad al medio, dada la escasa cantidad de sangre índica de esta cruza. Por este motivo se trabajó sobre la comparación del desempeño de los cruzamientos sobre la base de un rodeo de hembras Brangus 3/8 cruzadas con toros Brangus 3/8, Brahman y Angus y hembras Brahman, cruzadas con toros Brahman. El trabajo fue llevado a cabo en una estancia ubicada en el centro-norte de la Provincia de Corrientes. Se tomó el peso al nacer, ganancia diaria de peso vivo y peso ajustado a los 210 días. Los datos se analizaron estadísticamente y se expresaron en gráficos. Estadísticamente no se hallaron diferencias significativas, aunque entre los grupos hubo contrastes en la cantidad de $\mathrm{kg}$ de ternero destetado.
\end{abstract}

Palabras clave: ternero, cruzamientos, razas sintéticas, ganancia de peso.

\begin{abstract}
Varlamoff, N.B.; Cipolini, M.F.; Jacobo, R.A.; Martínez, D.E.; Ragazzi, A.: Weight gain from birth to weaning in Brahman and Brangus $1 / 4,3 / 8$ and 5/8 calves from Corrientes, Argentina. Rev. vet. 22: 1, 60-63, 2011. In the tropical environments the use of Bos indicus $\mathrm{x}$ Bos taurus cattle is an efficient tool to improve the production index in farms. Among different factors, weather affects production efficiency. Corrientes Province has a subtropical climate that restricts the development of cattle production. Such environmental conditions determine the breeding of adapted cattle, rustic and with high production levels. For these reasons, B. indicus (Brahman) and its derivative breeds are common in Northeastern Argentina, used in crossbreeding with European and synthetic breeds in different blood percentage, such as Braford or Brangus 1/4, 3/8, 5/8. In farms from Corrientes it was observed that cattle in many cases have $1 / 4$ Brahman blood percentage, being this a cause of loss of adaptability to environmental conditions. The purpose of this work was to compare the performance of different crossbred animals upon a base of Brangus $3 / 8$ females crossbred with Brangus $3 / 8$ Brahman and Angus bulls, and Brahman female crossbred with Brahman bulls. Assay was carried out in a farm located in the north-center region of Corrientes. Data regarding birth weight, daily live weight gain and weight adjusted to 120 days were recorded and then statistically analyzed. No significant differences were observed, but there were differences in weight of calves at weaning.
\end{abstract}

Key words: calf, crossbreed, synthetics breeds, weight gain. 


\section{INTRODUCCIÓN}

En los ambientes tropicales la utilización del cruzamiento de ganado Bos taurus x Bos indicus es una herramienta de gran utilidad para mejorar los índices productivos de un establecimiento ${ }^{2}$. El clima es un factor que afecta la eficiencia productiva por diversas causas, como son el permanente estrés calórico, pasturas pobres, escasez o exceso de agua, aspectos todos relacionados con épocas y fases críticas del animal. Estas circunstancias contribuyen a la aparición de enfermedades infecciosas y parasitarias, especialmente en las razas europeas ${ }^{7}$ y del mismo modo, podría afectar a las cruzas con mayor proporción de sangre europea.

Tanto las condiciones climáticas como nutricionales de la Provincia de Corrientes, obligan al productor a criar animales adaptados, rústicos y con un alto desempeño productivo. Para ello una opción disponible en la región es el uso de ganado Bos indicus o sus cruzas ${ }^{2}$. En Argentina la raza índica más utilizada para este propósito es la Brahman. Su incorporación a la ganadería de la zona norte del país produjo una verdadera revolución productiva. Según registros de la época, elevó el porcentaje de preñez del $25 \mathrm{al} 50 \%{ }^{2}$. Estos animales recorren los pastizales con facilidad y caminan grandes distancias para beber. Utilizan eficientemente gramíneas con alto porcentaje de fibra y tienen la capacidad de consumir una amplia variedad de forrajes, lo cual es una ventaja en las regiones tropicales y sub-tropicales. Son animales longevos; los toros mantienen su fertilidad hasta los 10 o 12 años y las vacas hasta los 15 años. Las vacas Brahman tienen un instinto materno más marcado que otras razas y están muy bien adaptadas a regiones de pastoreo extensivo bajo condiciones pobres de manejo ${ }^{1,2}$.

Estas bondades hacen del Brahman una herramienta de gran valor en los planteos productivos del norte argentino. El primer y mayor beneficio conocido del cruzamiento es el vigor híbrido (heterosis), mientras que el segundo beneficio es el efecto complementario de los rasgos beneficiosos de las diferentes razas ${ }^{4}$. En cuanto a los rodeos de cría, muchos autores han señalado los mayores beneficios de los cruzamientos de cebú por Bos taurus, al utilizar las vacas F1 para cría, informando un incremento de 25 a $35 \%$ en los $\mathrm{kg}$ de ternero destetado por vaca. Este incremento de la productividad es el resultado de una combinación de factores, siendo los más importantes la tasa de sobrevivencia de los terneros y la habilidad materna de las vacas cruza ${ }^{7,10,13,14}$. El comportamiento reproductivo de las vacas de cría y el peso al destete de los terneros producidos son el componente fundamental de la productividad del rodeo, ya que este grupo consume la mayor proporción de alimentos ${ }^{14}$.

Estudios de calidad de carne compararon el efecto del grado de sangre cebú, edad de faena y tiempo de maduración y determinaron que las carnes maduras de 7 o 14 días obtuvieron la clasificación de "tiernas". Además comprobaron que la proporción de sangre cebú no afectó la terneza. El ensayo utilizó animales Brangus de tipo $3 / 8$ y $5 / 8^{3}$. La forma más común de utilizar el ganado índico es en cruzamientos con razas europeas y sintéticas en diferentes proporciones, como Braford y Brangus $1 / 4,3 / 8,5 / 8$ y otras ${ }^{9}$.

En la zona se ha observado que la hacienda en muchos casos presenta características fenotípicas de 1/4 sangre Bos indicus y esto puede traer como consecuencia una pérdida de adaptabilidad al medio ${ }^{5}$ dada la escasa cantidad de sangre índica de esta cruza. Ello podría ser consecuencia de la constante utilización de ganado sangre tipo $3 / 8$, sin control de fenotipos de los productos, dejando en el rodeo animales resultantes de la segregación de los genes europeos ${ }^{6}$. Por este motivo se trabajó sobre la comparación del desempeño de los cruzamientos sobre la base de un rodeo de hembras Brangus tipo 3/8 cruzadas con toros Brangus 3/8, Brahman y Angus y hembras Brahman cruzadas con toros Brahman.

Esta comunicación es parte de un proyecto multidisciplinario cuyo objetivo es efectuar evaluaciones sanitarias, productivas y reproductivas comparando la raza Brahman pura con Brangus de diferentes porcentajes de sangre cebuina en el segmento de $1 / 4,3 / 8$ y 5/8. Particularmente, el presente trabajo tuvo como finalidad evaluar los datos de peso al nacimiento, ganancia diaria de peso y peso ajustado a los 210 días de los terneros productos de los diferentes cruzamientos.

\section{MATERIAL Y MÉTODOS}

El ensayo se llevó a cabo en un establecimiento dedicado a la actividad de cría bovina, ubicado en el Departamento de Concepción, Provincia de Corrientes. El mismo se halla en el límite entre las zonas de lomadas arenosas y depresión iberana ${ }^{8}$, entre las isotermas 21 y $20^{\circ} \mathrm{C}$ e isohietas 1.400 y $1.300 \mathrm{~mm}$ anuales.

Se trabajó sobre un rodeo de 50 hembras de 4 a 6 años, que fueron divididas en 4 grupos: uno de Brahman y tres de Brangus tipo 3/8. Sobre las vacas Brahman $(n=13)$ se realizó servicio natural con toros Brahman, y sobre las vacas Brangus se realizó inseminación artificial de la siguiente manera: las vacas Brangus 3/8 con caracteres fenotípicos que se aproximaban a un tipo $1 / 4$ sangre $(n=13)$ se inseminaron con Brahman, las vacas Brangus $3 / 8$ con caracteres fenotípicos que se aproximaban al tipo $5 / 8$ sangre $(n=8)$ se inseminaron con Angus, y las vacas Brangus 3/8 definidas fenotípicamente $(n=16)$ se inseminaron con Brangus $3 / 8$.

Los terneros nacieron entre los meses de agosto, septiembre y octubre del año 2009. Al nacer, los terneros fueron identificados con caravanas y pesados inmediatamente. Luego se pesaron individualmente a los días $30,60,90$ y 150 post-nacimiento, acumulando 5 pesadas hasta el momento del destete en el mes de junio. Durante todo el ensayo y hasta el destete los terneros se mantuvieron sobre pastura natural. Las medidas sanitarias consistieron en administración de Doramectina al nacer y luego cada vez que la carga de garrapa- 
tas (Boophilus microplus) lo requiriera. Las hembras se vacunaron contra brucelosis y todos los animales recibieron vacunación para prevenir enfermedades clostridiales y aftosa. Periódicamente se realizaron baños con Amitraz, según carga de garrapatas.

Se confeccionaron tablas utilizando el programa informático Microsoft Excel, donde se agruparon los terneros de acuerdo a la proporción de sangre cebú obtenida, se ajustó el peso a los 210 días, se obtuvo la ganancia diaria de peso vivo individual y grupal, desde

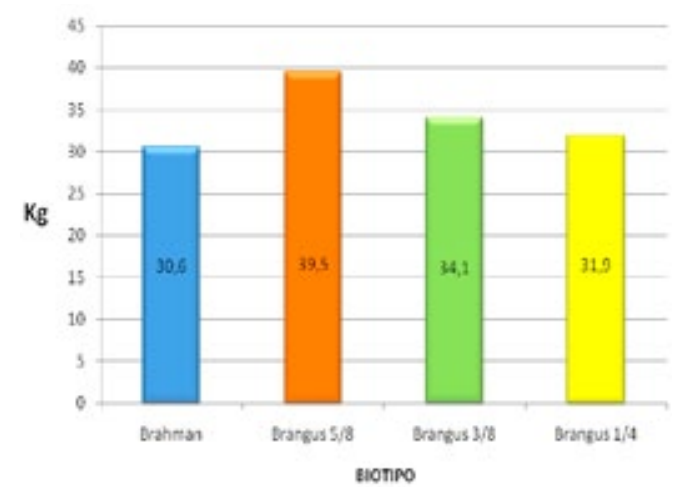

Figura 1. Peso al nacer, en cada uno de los grupos.

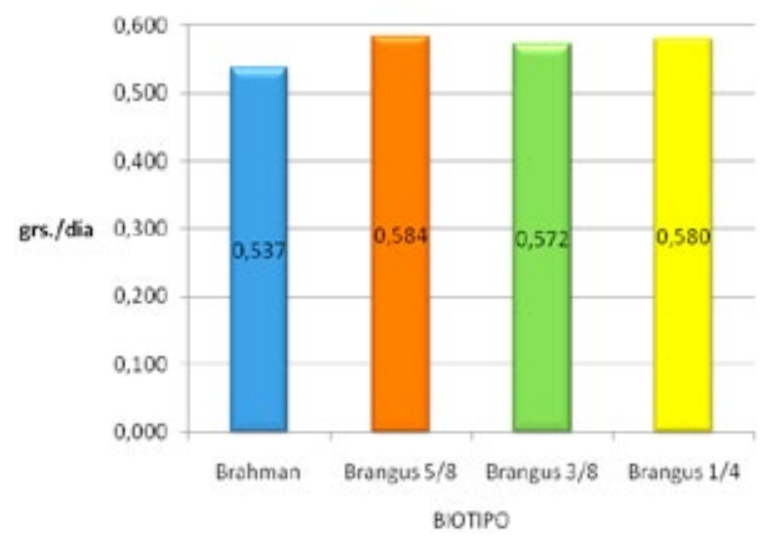

Figura 2. Ganancia diaria de peso vivo por grupo.

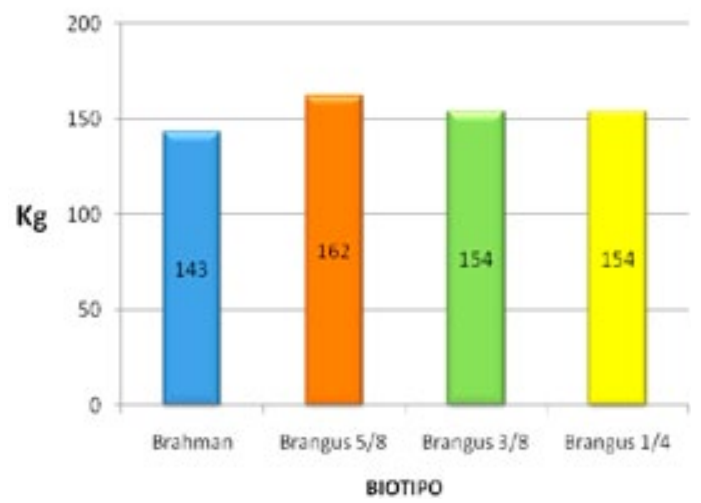

Figura 3. Peso ajustado a los 210 días. el nacimiento al destete. Los datos se analizaron mediante el software estadístico InfoStat, para determinar si existían diferencias significativas entre los grupos, para las variables ganancia de peso y peso ajustado a los 210 días. Se utilizó un diseño de bloques complentamente al azar, realizándose análisis de la variancia a dos vías (raza y tratamiento), así como comparación de medias por Test de Duncan $(\mathrm{p}<0,05)$.

\section{RESULTADOS Y DISCUSIÓN}

En las Figuras 1 al 4 se pueden observar los resultados en cuanto al peso al nacer de los terneros, las ganancias, el peso a los 210 días y la estimación de la evolución del peso respectivamente. El análisis de la varianza no arrojó diferencias estadísticamente significativas para el efecto cruza ni las variables como peso, ganancia diaria de peso y peso ajustado a los 210 días.

La Figura 1 muestra un mayor peso al nacer a favor del grupo Brangus tipo 5/8, atribuible probablemente al vigor híbrido de esta cruza, sumado a que tiene una gran proporción de sangre cebuina, lo cual incide en su mejor adaptación a las condiciones medioambientales en que se desarrolló el ensayo.

En la ganancia de peso (Figura 2) no se evidencian diferencias significativas entre cruzas. Para el peso ajustado a los 210 días (Figura 3) se registró una diferencia de $8 \mathrm{~kg}$ a favor del grupo Brangus tipo 5/8 respecto a los tipos $3 / 8$ y $1 / 4$, y de $16 \mathrm{~kg}$ a favor del Brangus tipo 5/8 respecto al Brahman. Esto puede ser atribuido a que los animales $5 / 8$ son de mayor frame que las otras dos cruzas evaluadas (3/8 y $1 / 4)$, por lo tanto crecen más rápido, además de reunir las características de mayor rusticidad y adaptabilidad al medio, con la condición carnicera de la raza europea.

En la Figura 4 se consigna una proyección estimada de la evolución del peso de las diferentes cruzas desde el nacimiento al destete, advirtiéndose que fueron favorecidos los tipos 5/8 y $1 / 4$ con $187 \mathrm{~kg}$, en ambos casos a los 240 días. Al grupo tipo 5/8 se le atribuye a un efecto de la raza paterna (Brahman) que aporta

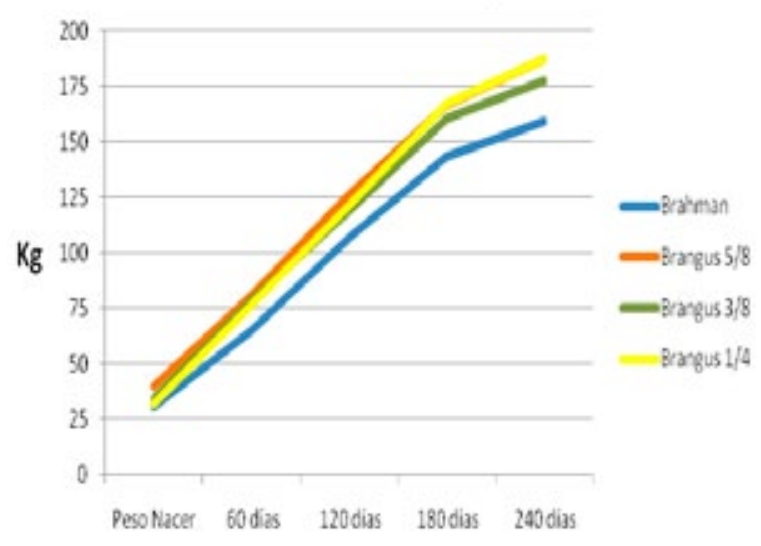

Figura 4. Estimación de la evolucion del peso. 
un frame mayor, mientras que para grupo tipo $1 / 4$ a un efecto materno, ya que las madres de estos terneros, por las condiciones de manejo de los cruzamientos en el establecimiento, responderían a características fenotípicas de hembras tipo acebuzado y estas tendrían una habilidad materna superior a las demás.

En coincidencia con estos resultados, en otro ensayo sobre cruzamiento alternado Brahman-Hereford, se determinó que los pesos al destete fueron mayores en aquellos terneros hijos de vacas $1 / 2$ sangre ${ }^{11}$. En una investigación realizada sobre terneros de distintas proporciones genéticas de Hereford y Brahman se encontró que los terneros $1 / 4$ sangre fueron los que obtuvieron el mayor peso, siendo estos hijos de vacas $1 / 2$ sangre $^{12}$.

En terneros Brahman, Hereford, 2/3 Brahman y $2 / 3$ Hereford, destetados precozmente en el noroeste de Corrientes, no se hallaron diferencias significativas de ganancia de peso entre lotes, aún así fue mayor en los terneros cruzas ${ }^{1}$. El mayor peso al inicio del ensayo fue el grupo $2 / 3$ Hereford, hecho atribuido a que eran hijos de madres acebuzadas y habían recibido buen aporte de leche. En cuanto al peso al final del ensayo resultó mayor en los terneros cruza, siendo el menor peso para los Hereford.

Sería importante continuar registrando la evolución de estos animales en su etapa de recría y hasta la edad de entore de las vaquillas, donde posiblemente, las 1/4 sangre sufrirán el rigor del ambiente en comparación con los otros cruzamientos. Cabe mencionar que, en un ensayo anterior realizado por los autores en el mismo rodeo (inédito), se evidenciaron diferencias en las ganancias de peso en vaquillas durante la época estival, en detrimento de las cruzas más europeizadas.

En conclusión, pese a no haberse registrado diferencias significativas entre los distintos cruzamientos, sí fueron halladas al analizar los distintos pesos y la diferencia en cantidad de $\mathrm{kg}$ de ternero, circunstancias que determinan mayor rentabilidad teniendo en cuenta que implican 10, 15 y $20 \mathrm{~kg}$ de diferencia entre un grupo y otro, lo cual trasladado a cientos de terneros significa considerable aumento de los ingresos por ventas.

\section{REFERENCIAS}

1. Arias Mañotti AA, Slobozian A, Revidatti MA, Capellari A. 1999. Factores genéticos y ambientales que influencian la ganancia de peso de terneros destetados precozmente en el N.O. de Corrientes. Anales XX Sesión Com Cientif Fac Cs Vet UNNE (Corrientes, Argentina), p. 23.

2. Arias Mañotti AA, López MV, Slobozian A. 2008. Evaluación genética de bovinos de raza Brahman en tres rodeos del nordeste argentino. Rev Arg Prod Anim 28: 113-142.

3. Balbuena O. 2004. Más madura y más tierna. Rev Brangus 26: 58-61.

4. Bob Frazer A. 2003. Cruzamiento ¿es bueno para su rodeo? Rev Hereford 67: 64-67.

5. Bossman D. 2006. Selección para la adaptabilidad del ganado vacuno. Anales Congr Ganad Norte Argent (Termas Río Hondo, Argentina), p. 38.

6. Canosa FR. 2003. Evaluación de diferentes biotipos Braford y cuarterón en sistemas de producción de cría en el NEA y NOA. Rev Braford 18: 10-13.

7. Córdova A, Rodríguez G, Córdova M, Córdova C, Pérez J. 2005. Ganancia diaria y peso al destete en terneros de cruces Bos taurus con Bos indicus en trópico húmedo. Rev Med Vet Zoot 10: 23-25.

8. Dirección de Estadística y Censos de la Provincia de Corrientes. 2010. Censo Nacional Agropecuario. On line: www.deyc-corrientes.gov.ar.

9. Lagos F. 1998. Cruzamientos entre bovinos de carne. Rev Oeste Ganad 1: 28-36.

10. López D. 2000. La formación de razas compuestas. Sumario Ganad (Buenos Aires) 3: 74-77.

11. López Valiente S. 2007. Cruzamientos Brahman-Hereford, ventajas y limitaciones de los cruzamientos alternados. Serie Técn INTA Mercedes (Corrientes, Argentina) 42: 8.

12. Mezzadra C, Miquel MC, Molinuevo H, Kramer S, Melussi L. 1984. Evaluación de caracteres de crecimiento en un cruzamiento alternado Brahman-Hereford. Rev Arg Prod Anim 4: 909-922.

13. Muller LA. 2000. La selección exige seriedad y orientación. Rev Brangus 22: 54-57.

14. Pittaluga O. 2005. Inclusión de genética cebuina para la mejora de la productividad en la fase de cría. Rev INIA 4: 6-10. 